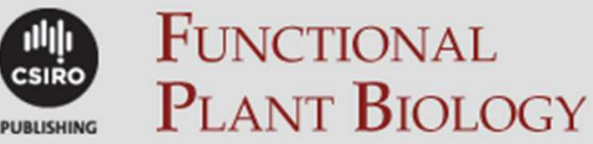

\title{
Estimation of the steady-state cyclic electron flux around Photosystem I in spinach leaf discs in white light, CO2- enriched air and other varied conditions
}

\begin{tabular}{|r|l|}
\hline Journal: & Functional Plant Biology \\
\hline Manuscript ID: & FP13010.R1 \\
\hline Manuscript Type: & Research paper \\
\hline Date Submitted by the Author: & $\mathrm{n} / \mathrm{a}$ \\
\hline Complete List of Authors: & $\begin{array}{l}\text { Kou, Jiancun; Northwest A\&F University, College of Animal Science \& } \\
\text { Technology } \\
\text { Takahashi, Shunichi; Australian National University, Research School of } \\
\text { Biology } \\
\text { Oguchi, Riichi; Australian National University, Research School of Biology } \\
\text { Fan, Da-Yong; The Chinese Academy of Sciences, Institute of Botany } \\
\text { Badger, Murray; Australian National University, Research School of Biology } \\
\text { Chow, Wah Soon; Australian National University, Research School of } \\
\text { Biology }\end{array}$ \\
\hline Keyword: & $\begin{array}{l}\text { Photosystem I, Photosynthesis, Irradiance, Water stress physiology, } \\
\text { Temperature stress }\end{array}$ \\
\hline
\end{tabular}


2 Estimation of the steady-state cyclic electron flux around Photosystem $I$ in spinach leaf 3 discs in white light, $\mathrm{CO}_{2}$-enriched air and other varied conditions

4 Jiancun Kou ${ }^{A, B}$, Shunichi Takahashi ${ }^{B}$, Riichi Oguchi ${ }^{B}$, Da-Yong Fan ${ }^{B, C}$, Murray R Badger $^{B}$ and 5 Wah Soon Chow $^{B, D}$

$6{ }^{A}$ College of Animal Science \& Technology, Northwest A\&F University, Yangling, Shaanxi 7712100, China.

$8{ }^{\mathrm{B}}$ Division of Plant Science, Research School of Biology, College of Medicine, Biology and 9 Environment, The Australian National University, Canberra, ACT 0200, Australia.

$10{ }^{\mathrm{C}}$ State Key Laboratory of Vegetation and Environmental Change, Institute of Botany, The

11 Chinese Academy of Sciences, 100093 Beijing, China.

12 DCorresponding author. E-mail: Fred.Chow@anu.edu.au

15 Running title: Estimation of cyclic electron flux around PS I 
Abbreviations: ATP, adenosine triphosphate; CEF, cyclic electron flux around Photosystem I; Chl, chlorophyll; DCMU: 3-(3,4-dichlorophenyl)-1,1-dimethyl-urea; ETR1, the total electron transport rate through PS I; ESC, electrochromic signal; $f_{\mathrm{I}}$, the fraction of absorbed light partitioned to PS I; $F_{\mathrm{m}}$ or $F_{\mathrm{m}}{ }^{\prime}$, maximum fluorescence in the fully relaxed dark state or in the light; $F_{\mathrm{o}}$ or $F_{\mathrm{o}}{ }^{\prime}$, minimum fluorescence in the fully relaxed dark state or in the light; $F_{\mathrm{s}}{ }^{\prime}$, relative steady-state $\mathrm{Chl}$ fluorescence yield in the light; $F_{\mathrm{v}}$ or $F_{\mathrm{v}}{ }^{\prime}$, variable fluorescence in the fully relaxed dark state or in the light, where $F_{\mathrm{v}}=F_{\mathrm{m}}-F_{\mathrm{o}}$ and $F_{\mathrm{v}}{ }^{\prime}=F_{\mathrm{m}}{ }^{\prime}-F_{\mathrm{o}}{ }^{\prime} ; F_{\mathrm{v}} / F_{\mathrm{m}}$ or $F_{\mathrm{v}}{ }^{\prime} / F_{\mathrm{m}}{ }^{\prime}$, ratio of variable to maximum $\mathrm{Chl}$ florescence yield in the dark-relaxed state or during illumination, respectively; FR, far-red light; $\mathrm{LEF}_{\mathrm{Fl}}$, the linear electron transport rate through PS II estimated by Chl fluorescence; $\mathrm{LEF}_{\mathrm{O} 2}$, the linear electron flux through PS II estimated by gross $\mathrm{O}_{2}$ evolution; MV, methyl viologen; $\mathrm{NAD}(\mathrm{P})$, nicotinamide adenine dinucleotide (phosphate); NPQ, non-photochemical quenching; P700, special chlorophyll dimer acting as the primary electron donor in PS I; PAM, pulse amplitude modulation fluorometer; $\phi_{\mathrm{NPQ}}$, the fraction of light absorbed by the PS II antennae that is dissipated thermally in a light-dependent manner; $\phi_{\mathrm{PS} \text { II }}$, photochemical yield of PS II; $P_{\mathrm{m}}, P_{\mathrm{m}}{ }^{\prime}$, maximum $\mathrm{P} 700^{+}$signal in weak FR light or actinic light, respectively; $\mathrm{Q}_{\mathrm{A}}$, primary quinone electron acceptor in PS II; $q P$, photochemical quenching parameter; RWC, relative water content; Y(I), photochemical yield of PS I.

\section{Abstract}

Cyclic electron flux (CEF) around Photosystem I (PS I) is essential for efficient photosynthesis and aids photoprotection, especially in stressful conditions, but the difficulty in quantifying CEF is non-trivial. The total electron flux through PS I (ETR1) and the linear electron flux $\left(\mathrm{LEF}_{\mathrm{O} 2}\right)$

40 through both photosystems in spinach leaf discs were estimated from the photochemical yield of

41 PS I and the gross oxygen evolution rate, respectively, in $\mathrm{CO}_{2}$-enriched air. $\Delta$ Flux $=\mathrm{ETR} 1-$

$42 \mathrm{LEF}_{\mathrm{O} 2}$ is an upper estimate of CEF. (1) Infiltration of leaf discs with $150 \mu \mathrm{M}$ antimycin A did 43 not affect $\mathrm{LEF}_{\mathrm{O} 2}$, but decreased $\Delta$ Flux 10 -fold. (2) $\Delta$ Flux was practically negligible below 350 
$44 \mu \mathrm{mol}$ photons $\mathrm{m}^{-2} \mathrm{~s}^{-1}$, but increased linearly above it. The following results were obtained at $45980 \mu \mathrm{mol}$ photons $\mathrm{m}^{-2} \mathrm{~s}^{-1}$. (3) $\Delta$ Flux increased 3-fold as the temperature increased from $5^{\circ} \mathrm{C}$ to $4640^{\circ} \mathrm{C}$. It did not decline at high temperature, even when $\mathrm{LEF}_{\mathrm{O} 2}$ decreased. (4) $\triangle \mathrm{Flux}$ increased 47 by $80 \%$ as the relative water content of leaf discs decreased from $100 \%$ to $40 \%$, when $\mathrm{LEF}_{\mathrm{O} 2}$ 48 decreased 2-fold. The method of using $\Delta$ Flux as a non-intrusive upper estimate of steady-state 49 CEF in leaf tissue appears reasonable when photorespiration is suppressed.

50

51

52

53

54

55

56

57

58

59

60

61

62

63

Key words: Antimycin A; cyclic electron flow; linear electron flow; P700; Photosystem I

\section{Introduction}

Arnon et al. (1955) demonstrated photophosphorylation on illumination of isolated thylakoids in the presence of vitamin $\mathrm{K}$ via a cyclic electron flux (CEF) around Photosystem I (PS I). Since CEF is essential for efficient photosynthesis (Munekage et al. 2004) and for photoprotection (Takahashi et al. 2009), there have been sustained efforts to elucidate the mechanisms and roles of this cyclic electron flow (for reviews, see Bendall and Manasse, 1995; Allen, 2003; Bukhov and Carpentier, 2004; Johnson, 2005; Joliot and Joliot, 2006; Shikanai 2007; Alric 2010; Miyake 2010; Kramer and Evans 2011). Achieving such an understanding, however, has been hampered by the difficulty of quantifying CEF in physiological conditions due to the absence of a net product of cyclic electron flow.

Methods for measuring/inferring $\mathrm{CEF}$ can be grouped into two categories, as summarized in Table 1. In Category (A), CEF is monitored directly, in at least three ways. (1) One way is to measure the transient increase in chlorophyll (Chl) fluorescence yield on cessation of actinic illumination; the increase reflects electron donation to the plastoquinone 
pool from reductants accumulated during illumination, and is suppressed by antimycin A (Mano et al. 1995). This way of monitoring CEF, however, is basically qualitative (Gotoh et al. 2010).

70

(2) A second way is to use an elaborate sequence of redox poising by pre-illumination of thylakoids in anaerobic conditions, followed by the addition of 3-(3,4-dichlorophenyl)-1,1dimethyl-urea (DCMU) to eliminate linear electron flow, and finally illumination with actinic light to monitor redox changes of ferredoxin in a light-to-dark transition (Cleland and Bendall, 1992). It was possible to deduce a value of CEF, but only in the absence of linear electron flow and in anaerobic conditions. (3) A third way is to use a modulated photoacoustic signal (Malkin and Canaani, 1994), induced by modulated actinic light, that has an amplitude depending on the absence or presence of a saturating light pulse; it has been used to indicate cyclic electron flow leading to energy storage in far-red actinic light (e.g. Herbert et al. 1990; Joët et al. 2002; Jeanjean et al. 2008). This method, however, is limited to the use of far-red actinic light, unless inhibitors are used to prevent the linear electron flux in white light (Canaani et al. 1989; Veeranjaneyulu et al. 1998), in which case the magnitude of CEF is altered because the redox poise is altered by inhibition of LEF.

In Category (B) ETR1, the total electron flux through PS I, is first estimated. Then by inhibiting/suppressing LEF, or estimating LEF independently without inhibiting it, or inhibiting CEF by methyl viologen (MV), a CEF can be obtained by difference. In this category, ETR1 can be measured in three ways. (i) One way is to use the electrochromic signal (ECS) in continuous actinic light of a particular spectral quality (reviewed by Bailleul et al. 2010) by monitoring the dark-interval relaxation kinetics (DIRK, Sacksteder and Kramer, 2000) or the "dark pulse" kinetics (Joliot and Joliot, 2002) of the proton current immediately after cessation of illumination. Joliot and Joliot (2002) used the post-illumination ECS kinetics to estimate the cyclic electron flow through PS I upon inhibition of PS II by DCMU, but the CEF so obtained is different from that in the absence of DCMU because of altered redox poising. In order to estimate CEF while the linear electron flux is occurring, Bailleul et al. (2010) subtracted a linear electron flow through PS II ( $\mathrm{LEF}_{\mathrm{Fl}}$, obtained from $\mathrm{Chl}$ fluorescence) from the proton flux 
obtained from the post-illumination ESC kinetics. However, the fluorescence signal reports from a certain depth of the leaf tissue (Oguchi et al. 2011). By contrast, the ECS signal indicates a whole-tissue property: the fast rise of the ECS signal can be used to obtain a stoichiometry of the two photosystems that agrees with that obtained from the entire population of the two photosystems (Fan et al. 2007a). Therefore, the difference between the postillumination proton flux and $\mathrm{LEF}_{\mathrm{Fl}}$ as a measure of $\mathrm{CEF}$ is subject to considerable uncertainty.

Subtraction of $\mathrm{LEF}_{\mathrm{F} 1}$ from the total proton current can be avoided by simply comparing the proton current between a drought-stress treatment and a control (Kohzuma et al. 2009), or a mutant and the wild type (Livingston et al. 2010) at the same $L E F_{F l}$. The extra proton current at a given $\mathrm{LEF}_{\mathrm{Fl}}$ is taken to be due to CEF. However, $\mathrm{LEF}_{\mathrm{Fl}}$ at a given irradiance that is greater than $300 \mu \mathrm{mol} \mathrm{m} \mathrm{s}^{-2}$ is different between the treatment and control, or between a mutant and the wild type, so the method is restricted to low irradiance, where CEF is small anyway. Another draw-back is that since the proton current obtained by the ECS method is in units $\mathrm{s}^{-1}$, calculating the CEF on a leaf area basis requires further information, such as the content of PS I reaction centres per unit leaf area.

(ii) A second way in Category B for measuring ETR1, in a number of variations, measures the total electron flux through PS I by monitoring the light-to-dark redox changes of P700 (the special chlorophyll dimer acting as the primary electron donor in PS I), recently with improved signal-to-noise ratio and time resolution (Klughammer and Schreiber, 1994; Laisk et al. 2010). This method, based on post-illumination $\mathrm{P} 700^{+}$re-reduction kinetics, sometimes uses DCMU to abolish linear electron flow (Maxwell and Biggins, 1976; Golding et al. 2004; Cardol et al. 2009), such that CEF remains as the predominant electron flow through PS I. Unfortunately, such CEF is different from that occurring in the absence of DCMU. In order to avoid the use of DCMU, Laisk et al. (2005) assayed the total electron flux through P700 (ETR1, obtained from a light-to-dark $\mathrm{P} 700^{+}$re-reduction signal transient), and used chlorophyll fluorescence to determine the rate of PS II electron transport, with the obvious problem of 
121 comparing different regions of the leaf tissue. In another variation, methyl viologen (MV) was

122 used to eliminate CEF, while allowing linear electron flow to occur (Fan et al. 2007b; Jia et al.

123 2008). However, MV itself retards linear electron flow to some extent during continuous

124 illumination (Jia et al. 2008; Fan et al. 2009), necessitating a correction of LEF in the presence

125 of MV before CEF is obtained as the difference in the total electron flux through PS I in the

126 absence and presence of MV. The correction factor is based on the assumption that the ratio of

$127 \mathrm{LEF}_{\mathrm{Fl}}$ estimated by chlorophyll fluorescence in the absence of MV to that in the presence of MV

128 is the same everywhere within the whole leaf tissue. Based on this assumption, the linear

129 electron flux through PS I in the presence of MV is multiplied by a single correction factor to 130 yield the corrected LEF, which is then subtracted from ETR1 to give CEF. However, since the 131 chlorophyll fluorescence signal is a localized indicator at a specific depth of the leaf tissue, 132 while the P700 redox signal is a whole-tissue signal (Oguchi et al. 2011), the assumption may 133 lead to an error. Another short-coming of using MV is that the duration of illumination at high 134 irradiance has to be limited in order to minimize the production of reactive oxygen species that may cause damage. A further variation of the method based on the $\mathrm{P} 700^{+}$light-dark signal uses

136 far-red actinic light to examine cyclic electron flow with little linear electron flow during 137 photosynthetic induction (Joliot and Joliot, 2005; Vredenberg and Bulychev, 2010), thereby 138 avoiding the use of DCMU. While the use of far-red actinic light is non-intrusive, it does not 139 give the CEF in white light which normally drives photosynthesis in nature. Laisk et al. (2010) determined the total electron flux through PS I from the post-illumination kinetics of $\mathrm{P} 700^{+}$rereduction and the linear electron flux by the rate of oxygen evolution in high $\mathrm{CO}_{2}$, both being

142 whole-tissue measurements. However, because far-red actinic light was necessary to sustain a 143 substantial oxidation level of $\mathrm{P} 700^{+}$for measurement of post-illumination re-reduction kinetics, 144 the study did not use white light.

(iii) A third way in Category B is to determine ETR1 from the photochemical yield of

146 PS I multiplied by the irradiance, the leaf absorptance and the fraction of light partitioned to PS 147 I $\left(f_{\mathrm{I}}\right)$. Miyake et al. (2005) and Huang et al. (2011) used this approach, but had to estimate the 
148 linear electron flux $\left(\mathrm{LEF}_{\mathrm{Fl}}\right)$ by $\mathrm{Chl}$ fluorescence. The difference between ETR1 and $\mathrm{LEF}_{\mathrm{Fl}}$ is 149 taken to be CEF. However, in this approach, different parts of the leaf tissue are again sampled 150 in measurements of ETR1 and $\mathrm{LEF}_{\mathrm{Fl}}$.

151 From the comparisons above, it is clear that quantification of CEF is not a trivial task. 152 In this study a method (iii in Table 1) was chosen that (a) estimates ETR1 from the PS I 153 photochemical yield, and $\mathrm{LEF}_{\mathrm{O} 2}$ from the gross rate of oxygen evolution under identical 154 illumination, both being whole-tissue measurements which, though often used individually in 155 other contexts, have not been applied in combination for estimating CEF; (b) is non-intrusive; (c) 156 uses white actinic light to simulate sunlight, since coloured light alters CEF; and (d) took note 157 of the important finding that a proper determination of the photochemical yield of PS I for 158 calculating the total electron flux through PS I requires strong far-red light immediately before 159 and during the application of a saturating light pulse (Siebke et al. 1997). This method is not 160 yet ideal, but probably yields a closer quantitative estimate of CEF than others so far. In this 161 study, it was applied to spinach leaf discs in a variety of treatments expected to influence CEF 162 and/or LEF. The overall aim of this study was to achieve a reasonable quantitative estimate of 163 CEF that will help to elucidate the roles and regulation of cyclic electron flow in vivo in leaf 164 tissue under white light.

\section{Materials and methods}

166 Plant growth

167 Spinacea oleracea L. (cv. Yates hybrid 102) plants were grown in a glasshouse (approximately $16830 / 15^{\circ} \mathrm{C}$, day/night). A nutrient mix (Aquasol, Hortico, Clayton, Australia) was supplemented 169 by a slow release fertilizer ('Osmocote', Scotts Australia Pty Ltd, Castle Hill). 
171 When required, leaf discs $\left(1.5 \mathrm{~cm}^{2}\right)$ were immersed in water or a selected concentration of 172 antimycin A, vacuum-infiltrated using a water-driven pump for about $30 \mathrm{~s}$, blotted with 173 absorbent paper, and allowed to evaporate off the excess intercellular water in darkness for a 174 total of 30 min before measurement.

\section{Water stress treatment}

176 Leaf discs were allowed to lose water in a desiccator, aided by a battery-powered fan. Relative 177 water content was calculated as:

$178 \mathrm{RWC}=100 \times($ Fresh weight - Dry Weight $) /($ Turgid weight - Dry weight $)(\%)$.

179 Each leaf disc was subjected to cumulative losses of water content, with measurements made at 180 each chosen stage of dehydration.

\section{Linear electron flux measured by $\mathbf{O}_{2}$ evolution}

$182 \mathrm{O}_{2}$ evolution was measured in a gas-phase oxygen electrode (Hansatech, King's Lynn, UK) 183 chamber, thermosttated at $25^{\circ} \mathrm{C}$ unless specified otherwise, that accepted a multifurcated light 184 guide, and contained $1 \% \mathrm{CO}_{2}$ supplied by fabric matting moistened with $1 \mathrm{M} \mathrm{NaHCO} / \mathrm{Na}_{2} \mathrm{CO}_{3}$ 185 (pH 9). White incandescent light from a projector halogen lamp filtered by a Calflex $\mathrm{C}$ heat186 reflecting filter (Linos Photonics, Göttingen, Germany) and neutral-density filters was used to 187 illuminate a leaf disc. $\mathrm{O}_{2}$ evolution was measured over several minutes until steady state. The 188 post-illumination drift was subtracted algebraically from the steady-state net oxygen evolution 189 rate, and the gross oxygen evolution rate so obtained was multiplied by four to give the linear 190 electron flux, $\mathrm{LEF}_{\mathrm{O} 2}$. For calibration of the oxygen signals, $1 \mathrm{~mL}$ of air at $25^{\circ} \mathrm{C}$ (taken to 191 contain $8.05 \mu \mathrm{mol} \mathrm{O}_{2}$ ) was injected into the gas-phase $\mathrm{O}_{2}$ electrode chamber that was 192 thermostatted at a selected temperature. 


\section{Measurement of redox kinetics of P700}

194 Redox changes of P700 were observed with a dual wavelength (820/870 nm) unit (ED-P700DW) 195 attached to a PAM fluorometer (Walz, Effeltrich, Germany) in the reflectance mode (response 196 time constant $=95 \mu \mathrm{s}$ ). The reflectance mode (with a metal mesh under the leaf sample to 197 reflect the near infra-red radiation,) was chosen for convenience. Previously, it was shown that 198 the variation of the relative size of the $\mathrm{P} 700^{+}$signal with far-red irradiance was practically 199 identical for measurements in the reflectance or transmission modes (Kim et al. 2001). Oguchi 200 et al. (2011) also showed that the reflectance mode measures the whole tissue. Before

201 measurements, a leaf disc was brought to steady-state photosynthesis by illuminating it with white actinic light for about ten minutes for simultaneous measurement of $\mathrm{O}_{2}$ evolution and Chl fluorescence yields. To retain steady state for $\mathrm{P} 700^{+}$measurements, immediately after these simultaneous measurements, each leaf disc was re-illuminated with the same actinic light for $9.016 \mathrm{~s}$, using an electronic shutter controlled by one terminal of a pulse/delay generator (Model 555, Berkeley Nucleonics, USA).

During each 9.016-s illumination, at time $T=8.80 \mathrm{~s}$ (corresponding to the time point $t$ $=-50 \mathrm{~ms}$ in Fig. 1a), data acquisition (using software written by the late A. B. Hope) was started by a second terminal of the pulse/delay generator. At $T=8.85 \mathrm{~s}$, a strong far-red light (FR, $\sim 2000 \mu \mathrm{mol} \mathrm{m} \mathrm{m}^{-2} \mathrm{~s}^{-1}$ ) from a light-emitting diode array $(741 \mathrm{~nm} \pm 13 \mathrm{~nm}$, LED735-66-60, Roithner LaserTechnik, Vienna, Austria) was triggered on for $100 \mathrm{~ms}$ using a third terminal of the pulse/delay generator. The strong FR light depleted electrons from the inter-system chain, so that the subsequent saturating pulse (see below) oxidized P700 maximally (Siebke et al. 1997). While the strong FR light was on, at $T=8.90 \mathrm{~s}$, a saturating light pulse $\left(\sim 9000 \mu \mathrm{mol} \mathrm{m}{ }^{-2}\right.$ $\mathrm{s}^{-1}$ ) was applied for $10 \mathrm{~ms}$ by a pulse from a fourth terminal of the pulse/delay generator, yielding the maximally-oxidized $P_{\mathrm{m}}{ }^{\prime}$ signal in Fig. $1 a$. Finally, the white actinic light was turned off by the electronic shutter (at $T=9.016 \mathrm{~s}$ ). Data acquisition continued for $85 \mathrm{~ms}$ after cessation of actinic illumination to obtain the baseline corresponding to complete reduction of 
219 P700. Immediately after completion of one cycle of illumination and data acquisition (at $T=$ $2209.101 \mathrm{~s}$ ), another 9.016-s illumination was restarted, thereby maintaining steady-state 221 photosynthesis. Nine traces were averaged automatically to improve the signal-to-noise ratio.

Next, we determined the maximum photo-oxidizable P700 content. We established a 223 steady state by illumination with weak continuous far-red light $\left(\sim 12 \mu \mathrm{mol} \mathrm{m}{ }^{-2} \mathrm{~s}^{-1}, 723 \mathrm{~nm}\right)$ for $224>10 \mathrm{~s}$ (Fig. 1b). Then we superimposed a saturating single-turnover flash. Flashes were given 225 at $0.2 \mathrm{~Hz} ; 9$ consecutive signals were automatically averaged. The maximum signal, $P_{\mathrm{m}}$, 226 immediately after the flash was used to normalize the signal interval $b$ in Fig. $1 a$. The 227 photochemical yield of PS I is then given by $\mathrm{Y}(\mathrm{I})=b / P_{\mathrm{m}}$ (Klughammer and Schreiber 2007). 228 ETR1 was calculated as

$$
\mathrm{ETR} 1=\mathrm{Y}(\mathrm{I}) \times I \times 0.85 \times 0.5
$$

where $I$ is the irradiance, 0.85 is the assumed absorptance and 0.5 the assumed fraction $\left(f_{\mathrm{I}}\right)$ of absorbed white light partitioned to PS I. An experimental estimation of $f_{\mathrm{I}}$ in special cases is 232 given in Table 2.

The rate of electron transport through PS II measured by Chl fluorescence

Before measurement of $\mathrm{O}_{2}$ evolution, we measured the relative $\mathrm{Chl}$ fluorescence yield (blue excitation light, detection of all fluorescence $>660 \mathrm{~nm})$ in the dark-acclimated state $\left(F_{\mathrm{o}}\right)$ and after complete closure of traps $\left(F_{\mathrm{m}}\right)$ on application of a 0.8 -s saturating light pulse $(\sim 9000 \mu \mathrm{mol}$ $\left.\mathrm{m}^{-2} \mathrm{~s}^{-1}\right)$. Then, simultaneously with measurement of $\mathrm{O}_{2}$ evolution, the relative $\mathrm{Chl}$ fluorescence yield at steady state $\left(F_{\mathrm{s}}\right)$ and the maximum relative yield during illumination $\left(F_{\mathrm{m}}{ }^{\prime}\right)$ were measured using a PAM 101 fluorometer (Walz, Effeltrich, Germany). The effective quantum yield of PS II photochemistry (Genty et al. 1989), $\phi_{\mathrm{PS} \mathrm{II}}=\left(1-F_{\mathrm{S}} / F_{\mathrm{m}}{ }^{\prime}\right)$, was used to calculate the rate of electron transport through PS II $\left(\mathrm{LEF}_{\mathrm{Fl}}\right)$ as $\mathrm{LEF}_{\mathrm{Fl}}=\left(1-F_{\mathrm{S}} / F_{\mathrm{m}}{ }^{\prime}\right) \times I \times 0.85 \times 0.5$ with the same values of leaf absorptance and partitioning of light energy between PS II and PS I as used

243 in calculating ETR1. 
Photochemical quenching $(q P)$ was calculated as $\left(F_{\mathrm{m}}{ }^{\prime}-F_{\mathrm{s}}\right) /\left(F_{\mathrm{m}}{ }^{\prime}-F_{\mathrm{o}}{ }^{\prime}\right)$ (Krause and

245 Weis 1991), where $F_{\mathrm{o}}{ }^{\prime}$ was calculated according to Oxborough and Baker (1997). The fraction

246 of light absorbed by the PS II antennae that is dissipated thermally via $\Delta \mathrm{pH}$ - and xanthophylls-

247 regulated processes $\left(\phi_{\mathrm{NPQ}}\right)$ was calculated as $\left(F_{\mathrm{s}} / F_{\mathrm{m}}{ }^{\prime}\right)-\left(F_{\mathrm{s}} / F_{\mathrm{m}}\right)$, (Hendrickson et al. 2004).

All measurements of oxygen evolution, P700 kinetics and chlorophyll fluorescence were made on a leaf disc placed in a gas-phase $\mathrm{O}_{2}$ electrode chamber 250 thermostatted at $25^{\circ} \mathrm{C}$ or at the temperatures specified.

\section{Results}

\section{Estimation of the fraction of absorbed light $\left(f_{\mathrm{I}}\right)$ partitioned to PS I}

253 Estimation of the total electron flux through PS I according to Equation 1 requires information 254 on $f_{\mathrm{I}}$, the fraction of absorbed light partitioned to PS I. To estimate $f_{\mathrm{I}}$, we consider some special 255 cases in which CEF is likely to be small or negligible (Table 2). These special cases occur 256 where antimycin A was used to inhibit CEF (see Fig. 2 below) or when light at low irradiance 257 was used to drive linear electron flow but possibly little CEF (see Fig. 3 below). Consider leaf 258 discs infiltrated with $150 \mu \mathrm{M}$ antimycin A and exposed to $980 \mu \mathrm{mol}$ photons $\mathrm{m}^{-2} \mathrm{~s}^{-1}$. Assuming 259 that inhibition of CEF by antimycin A was complete, ETR1 would approximately equal $\mathrm{LEF}_{\mathrm{O} 2}$. 260 The measured $\mathrm{Y}(\mathrm{I})$ was 0.403 , from which Equation 1 , with $f_{\mathrm{I}}$ replacing 0.5 and $\mathrm{LEF}_{\mathrm{O} 2}(=165$ $261 \mu \mathrm{mol} \mathrm{e}^{-} \mathrm{m}^{-2} \mathrm{~s}^{-1}$ ) replacing ETR1, could be used to estimate $f_{\mathrm{I}}$ to be 0.49 . Similarly, infiltration 262 with $200 \mu \mathrm{M}$ antimycin A and exposure to $980 \mu \mathrm{mol}$ photons $\mathrm{m}^{-2} \mathrm{~s}^{-1}$ gave an estimated $f_{\mathrm{I}}=0.47$. 263 At moderately low irradiance such as 236 and $352 \mu \mathrm{mol}$ photons $\mathrm{m}^{-2} \mathrm{~s}^{-1}$, assuming that CEF 264 was negligible in $\mathrm{CO}_{2}$-enriched air, we estimated $f_{\mathrm{I}}$ to be 0.45 and 0.48 , respectively (Table 2). 265 As an approximation, we assumed $f_{\mathrm{I}}$ to be 0.50 in the calculation of ETR1 according to Equation 2661 , in all the results below. 


\section{Electron fluxes in response to antimycin A}

Antimycin A inhibits the ferredoxin-dependent CEF (Moss and Bendall, 1984; Ivanov et al. 1998). We monitored the electron fluxes as a function of [antimycin A] at $980 \mu \mathrm{mol} \mathrm{m}^{-2} \mathrm{~s}^{-1}$ (Fig. 2a). ETR1 decreased towards an asymptotic value. However, the inhibitor had no effect on $\mathrm{LEF}_{\mathrm{O} 2}$ assayed by gross $\mathrm{O}_{2}$ evolution. The difference ( $\Delta$ Flux) between the two fluxes decreased steadily with increase in [antimycin A], eventually down to about $10 \%$ of the control. As $\Delta$ Flux decreased, the fraction of excitation energy dissipated non-photochemically in a lightregulated manner $\left(\phi_{\mathrm{NPQ}}\right.$ ) decreased by about $34 \%$ (Fig. $2 b$ ), despite the constancy of $\mathrm{LEF}_{\mathrm{O} 2}$.

\section{Electron fluxes in response to irradiance of white light}

ETR1, the total electron flux through PS I, did not show saturation even at the highest irradiance of white light used (Fig. 3). By contrast $\mathrm{LEF}_{\mathrm{O} 2}$, assayed as the gross rate of $\mathrm{O}_{2}$ evolution multiplied by 4 , peaked at about $1500 \mu \mathrm{mol}$ photons $\mathrm{m}^{-2} \mathrm{~s}^{-1}$. The maximum $\mathrm{LEF}_{\mathrm{O} 2}$ was about $188 \mu \mathrm{mol}$ electrons $\mathrm{m}^{-2} \mathrm{~s}^{-1}$ (gross $\mathrm{O}_{2}$ evolution rate, $47 \mu \mathrm{mol} \mathrm{m}^{-2} \mathrm{~s}^{-1}$ ). The difference between ETR1 and $\mathrm{LEF}_{\mathrm{O} 2}(=\Delta$ Flux $)$, was negligibly small below $350 \mu \mathrm{mol} \mathrm{m} \mathrm{m}^{-2} \mathrm{~s}^{-1}$ above this threshold, it increased approximately linearly with irradiance (Fig. 3). At the highest irradiance, $\Delta$ Flux almost equalled $\mathrm{LEF}_{\mathrm{O} 2}$.

The gas-phase $\mathrm{O}_{2}$ electrode chamber also allowed us to examine $\mathrm{LEF}_{\mathrm{Fl}}$, the linear electron flux obtained from $\mathrm{Chl}$ fluorescence, under identical illumination conditions. $\mathrm{LEF}_{\mathrm{FL}}$ roughly matched $\mathrm{LEF}_{\mathrm{O} 2}$ evolution at irradiance $<250 \mu \mathrm{mol} \mathrm{m} \mathrm{m}^{-2} \mathrm{~s}^{-1}$; however, at higher irradiance it was less than the whole-tissue linear electron flux measured by gross $\mathrm{O}_{2}$ evolution, the discrepancy increasing with irradiance. 
289 At $980 \mu \mathrm{mol}$ photons $\mathrm{m}^{-2} \mathrm{~s}^{-1}$, ETR1 increased steadily with temperature, peaking at about $30^{\circ} \mathrm{C}$

290 but decreasing above this temperature (Fig. 4). $\mathrm{LEF}_{\mathrm{O} 2}$ assayed by $\mathrm{O}_{2}$ evolution followed a 291 similar pattern, though peaking slightly below $30^{\circ} \mathrm{C}$. The difference, $\Delta \mathrm{Flux}$, increased steadily 292 with temperature, showing no decline at $40^{\circ} \mathrm{C}$. Notably, at the extreme temperatures, $\Delta$ Flux 293 approached $\mathrm{LEF}_{\mathrm{O} 2}$. At all the temperatures tested, $\mathrm{LEF}_{\mathrm{O} 2}$ exceeded $\mathrm{LEF}_{\mathrm{F} 1}$; this was particularly 294 true at low temperatures.

\section{Electron fluxes in response to loss of leaf water content}

296 At $980 \mu \mathrm{mol}$ photons $\mathrm{m}^{-2} \mathrm{~s}^{-1}$, as the water content of leaf discs decreased from $100 \%$ to $55 \%$, 297 ETR1 increased slightly but decreased at water content $<55 \%$ (Fig. 5). $\mathrm{LEF}_{\mathrm{O} 2}$, assayed by 298 gross oxygen evolution, remained fairly constant between $100 \%$ and $55 \%$; it then decreased at 299 leaf water content $<55 \%$. Consequently, $\Delta$ Flux increased by about $80 \%$ as the water content 300 decreased from $100 \%$ to $40 \%$.

\section{DISCUSSION}

Notable features of our method that gives $\triangle$ Flux as an upper estimate of CEF

Our method measures (1) the total electron flux through PS I (ETR1) via the photochemical

305 yield of PS I and (2) $\mathrm{LEF}_{\mathrm{O} 2}$ by the gross rate of oxygen evolution (multiplied by four) under 306 identical white-light illumination. By difference $\Delta$ Flux was obtained as an upper estimate of 307 CEF, since ETR1 includes not only CEF, but also electron fluxes associated with the water308 water cycle, electron donation from stromal reductants and direct charge recombination in PS I, 309 though photorespiration can be excluded in $1 \% \mathrm{CO}_{2}$. An important aspect of our method is the 310 introduction of a strong far-red light pulse before and during a saturating pulse for measuring 311 total electron flux thorough PS I (Fig. 1a); without the strong far-red light pulse, the 
312 photochemical yield (and hence ETR1) could be under-estimated by as much as $18 \%$ (Siebke et $313 a l .2000)$. Another aspect is the use of a saturating single-turnover flash superimposed on weak 314 continuous far-red light to obtain the maximum photo-oxidizable P700 signal (Fig. 1b), in order 315 to avoid the use of a long saturating pulse which may cause some reduction of $\mathrm{P} 700^{+}$while 316 being used to photo-oxidize P700 fully. Our method offers some advantages. illumination conditions, in which the intra-leaf gradient of light should be also identical. The intra-leaf gradient of light determines the rate of excitation of both photosystems at different

320 depths of tissue, but both measurements were affected in parallel as the depth increased.

321 Further, both are whole-tissue measurements. That the $\mathrm{P} 700^{+}$signal is a whole tissue 322 measurement is demonstrated by the observation that the cumulative delivery of electrons from 323 PS II to $\mathrm{P} 700^{+}(\Sigma)$ following a saturating single-turnover flash was well correlated with the oxygen yield per saturating single-turnover flash, when both parameters were varied by a photoinhibition pre-treatment (Losciale et al. 2008). The same "calibration" straight line applied to all the plant species tested, regardless of differences in intra-leaf anatomy; by contrast,

327 the correlation of the $\mathrm{Chl}$ fluorescence parameter $F_{\mathrm{v}} / F_{\mathrm{m}}$ with the oxygen yield per saturating 328 single-turnover flash varied greatly among the same samples (Losciale et al. 2008). Further, 329 following a photoinhibition pre-treatment, a simple integration akin to $\Sigma$ was affected to the 330 same relative extent (compared with a control), regardless of whether the $\mathrm{P} 700^{+}$signal was measured from the adaxial or abaxial side of the leaf (Oguchi et al. 2011). Indeed, that the

$332 \mathrm{P} 700^{+}$signal is a whole-tissue measurement is to be expected. Since an $820-\mathrm{nm}$ measuring 333 photon is hardly absorbed by neutral $\mathrm{Chl}$ molecules and other pigments, such that leaf 334 absorptance is negligible above $750 \mathrm{~nm}$ (McCree 1972), it undergoes multiple scattering within 335 the leaf tissue, visiting many chloroplasts before being absorbed by a $\mathrm{P} 700^{+}$. By contrast, Chl fluorescence is a localized reporting signal, generally indicating shallower depths in the tissue, where the actinic light is attenuated less drastically and where 
338 any fluorescence is less readily re-absorbed on its way to the detector. The comparatively high 339 light in the shallower parts of the tissue tends to (1) reduce $\mathrm{Q}_{\mathrm{A}}$ more, thereby decreasing $q P$ and 340 (2) decrease $F_{\mathrm{v}}{ }^{\prime} / F_{\mathrm{m}}{ }^{\prime}$, the photochemical efficiency of open PS II traps, by virtue of the greater 341 trans-thylakoid $\Delta \mathrm{pH}$ in a higher-irradiance local environment (Terashima et al. 2009). 342 Consequently, $\mathrm{LEF}_{\mathrm{Fl}}$ becomes an under-estimation because its calculation includes $\phi_{\mathrm{PS} \text { II }}(=q P \times$ $\left.343 F_{\mathrm{v}}{ }^{\prime} / F_{\mathrm{m}}{ }^{\prime}\right)$. This is supported by the observation that the electron transfer rate measured via 344 chlorophyll fluorescence with red measuring light is lower than the rate measured with gas345 exchange measurement (Tsuyama et al. 2003). The difference between ETR1 and $\mathrm{LEF}_{\mathrm{F} 1}$ is, 346 therefore, expected to over-estimate CEF even more. Indeed, if we had used $\mathrm{LEF}_{\mathrm{Fl}}$ instead of $347 \mathrm{LEF}_{\mathrm{O} 2}$ as a measure of linear electron flow, $\mathrm{CEF}$ would have been even more over-estimated in 348 all of our treatments (Fig. 3). Further, the depth of fluorescence signal detection may vary with, 349 for example, (1) the actinic irradiance which determines the intra-leaf light gradient, (2) plant 350 species having different intra-leaf anatomy, (3) the colour of the measuring light and (4) the 351 extent of photoinhibition which affects the relative contribution of different depths of tissue to 352 the total signal. Therefore, the difference between ETR1 and $\mathrm{LEF}_{\mathrm{Fl}}$ as an estimate of CEF 353 presents considerable uncertainty.

Second, our method allows measurement under non-intrusive conditions, using white 355 light that resembles sunlight. It is free, for example, from special conditions used in the past to 356 quantify cyclic electron flow, including (1) far-red-enriched light to ensure substantial photo357 oxidation of $\mathrm{P} 700$ for measurement of the post-illumination $\mathrm{P} 700^{+}$re-reduction kinetics (e.g. Jia 358 et al. 2008; Fan et al. 2009; Laisk et al. 2010); (2) the use of MV to abolish CEF (e.g. Jia et al. 359 2008; Fan et al. 2009; Kohzuma et al. 2009); (3) correction for partial inhibition of PS II by MV 360 (Jia et al. 2008; Fan et al. 2007b, 2009); and (4) the use of DCMU to inhibit LEF so that the 361 residual electron flux through PS I could be attributed to cyclic flow alone (e.g. Maxwell and 362 Biggins 1976; Golding et al. 2004). Such restrictive conditions do not yield the magnitude of 
363 CEF in vivo under white light in physiological conditions where linear electron flow occurs 364 concurrently.

366 Our method, however, does have its assumptions and limitations. First, it assumes that light is 367 partitioned equally between the two photosystems when calculating ETR1; that is, the fraction 368 of light partitioned to PS I $\left(f_{\mathrm{I}}\right)$ is assumed to equal 0.50 in all conditions. This assumption, in 369 widespread use in the literature for calculating $\mathrm{LEF}_{\mathrm{F} 1}$ from $\mathrm{Chl}$ fluorescence measurements, is 370 probably reasonable for steady-state photosynthesis (Schreiber 2004), particularly in white light.

371 The values of $f_{\mathrm{I}}$ was estimated under some special conditions in which CEF was expected to be 372 minimal (Table 2). The values of $f_{\mathrm{I}}$ so estimated were not far from 0.50 . reaction is negligible in the conditions of the present study. Photorespiration was suppressed by high (1\%) $\mathrm{CO}_{2}$ during the measurements. On the other hand, our method is limited to situations

376 where photorespiration is inhibited. A potential improvement in the method is to measure 377 oxygen evolution while allowing photorespiration to occur, and to quantify the photorespiration rate so that it can be taken into account when calculating $\mathrm{LEF}_{\mathrm{O} 2}$.

As for the potentially oxygen-consuming Mehler reaction, the reactive oxygen produced by the reaction is scavenged by the enzymes of the water-water cycle, which leads to no net release or uptake of $\mathrm{O}_{2}$ (Miyake 2010). Therefore, there should be no significant effect of the Mehler reaction on the $\mathrm{LEF}_{\mathrm{O} 2}$ measurements, particularly in the steady-state and when cyclic electron flow is unimpeded. However, unlike $\mathrm{LEF}_{\mathrm{O} 2}$, ETR1 should include (pseudo-cyclic) electron flow associated with the water-water cycle. Therefore, the difference between ETR1 and $\mathrm{LEF}_{\mathrm{O} 2}$ would include such pseudo-cyclic electron flow, and would over-estimate $\mathrm{CEF}$, but not by as much as when $\mathrm{LEF}_{\mathrm{Fl}}$ assayed by $\mathrm{Chl}$ fluorescence is used in the subtraction.

387 Nevertheless, pseudo-cyclic electron flow should normally be relatively small, particularly in 
$388 \mathrm{CO}_{2}$-enriched air. By using mass spectrometry with wild-type tobacco, Ruuska et al. (2000) 389 reported an ${ }^{18} \mathrm{O}_{2}$ uptake rate of $3.4 \mu \mathrm{mol} \mathrm{m} \mathrm{s}^{-1}$ in the dark and $4.6 \mu \mathrm{mol} \mathrm{m} \mathrm{m}^{-2}$ in the light $390\left(970 \mu \mathrm{mol}\right.$ photons $\mathrm{m}^{-2} \mathrm{~s}^{-1}$ ), with $20 \% \mathrm{O}_{2}$ and $1 \% \mathrm{CO}_{2}$ in both the dark and the light. Taking the 391 respiration rate in the light to be $36 \%$ of that in darkness (Atkin et al. 2000), a respiration rate of $392(3.4 \times 0.36)=1.2 \mu \mathrm{mol} \mathrm{m}{ }^{-2} \mathrm{~s}^{-1}$ in the light is obtained; consequently, the ${ }^{18} \mathrm{O}_{2}$ uptake not due to 393 respiration in the light (attributable to the Mehler reaction) is $4.6-1.2=3.4 \mu \mathrm{mol} \mathrm{m} \mathrm{m}^{-2} \mathrm{~s}^{-1}$, 394 which is only about $8 \%$ of the (gross) ${ }^{16} \mathrm{O}_{2}$ evolution rate in the light (Ruuska et al. 2000). 395 Similarly, Vredenberg and Bulychev (2010) calculated that the Mehler reaction declines during 396 photosynthetic induction. Further, the water-water cycle in leaves is not a major alternative electron sink for dissipation of excess excitation energy even when $\mathrm{CO}_{2}$ assimilation is restricted (Driever and Baker 2012). These findings imply that the effect of the Mehler reaction on ETR1 is relatively small in the steady state. The residual antimycin-insensitive $\Delta$ Flux in the presence of high [antimycin A], ca. $10 \%$ of the control value (Fig. 2a), could include such pseudo-cyclic electron flow. Equally, it could also include NAD(P)H dehydrogenase-dependent cyclic electron flow or direct charge recombination within PS I.

Under extreme conditions where the Mehler reaction overwhelms the enzymes of the water-water cycle, the $\mathrm{O}_{2}$ uptake by the Mehler reaction could lead to an under-estimation of the

$405 \mathrm{LEF}_{\mathrm{O} 2}$ measured by net $\mathrm{O}_{2}$ evolution. Then the difference between ETR1 and LEF may further 406 over-estimate ferredoxin-dependent CEF.

If the assumptions and approximations of this method can be further validated, and if 408 photorespiaration can be reliably measured, it should be feasible to make a portable version of 409 the equipment with the appropriate software for use in the field.

410 Tests of the method in treatments expected to vary CEF and/or LEF

411 Antimycin A 
412 Antimycin A is often used as an inhibitor of ferredoxin-dependent cyclic electron flow (Endo et

413 al. 1997; Ivanov et al. 1998). As expected, it decreased $\Delta$ Flux to a low value (about $10 \%$ of the

414 control) at 150 and $200 \mu \mathrm{M}$ (Fig. $2 a$ ). This observation suggests that the ferredoxin-dependent

415 cyclic pathway is the main form of cyclic electron flow, and that the NAD $(\mathrm{P}) \mathrm{H}$ dehydrogenase-

416 dependent pathway may be relatively small. Interestingly, with the inhibition of cyclic electron

417 flow, $\phi_{\mathrm{NPQ}}$ also decreased (by about $33 \%$, Fig. $2 b$ ) when $\mathrm{LEF}_{\mathrm{O} 2}$ was constant. Possibly, cyclic

418 electron flow contributed to the trans-thylakoid $\triangle \mathrm{pH}$, such that inhibition of CEF diminished the

$419 \Delta \mathrm{pH}$ - and xanthophyll cycle-dependent non-photochemical quenching. Indeed, CEF-dependent

420 generation of a $\Delta \mathrm{pH}$ helps to alleviate photoinhibition by at least two distinct photoprotective

421 mechanisms (Takahashi et al. 2009). Any pseudo-cyclic electron flux associated with the

422 Mehler reaction would also contribute to the trans-thylakoid $\Delta \mathrm{pH}$ and hence to $\phi_{\mathrm{NPQ}}$. However,

423 the decrease in $\phi_{\mathrm{NPQ}}$ in the presence of antimycin A cannot be attributed to pseudo-cyclic

424 electron flow, since, if anything, pseudo-cyclic electron flow should increase when CEF is

425 inhibited.

426 Increasing irradiance

$427 \Delta$ Flux was negligibly small at irradiances $<350 \mu \mathrm{mol} \mathrm{m}^{-2} \mathrm{~s}^{-1}$ (Fig. 3). This is expected since

428 the carbon reduction cycle was able to use the majority of NADPH at low irradiance, leaving

429 little spare reduced ferredoxin for poising cyclic electron flow. At maximum $\mathrm{LEF}_{\mathrm{O} 2}$, however, 430 more reduced ferredoxin would be available for competition between $\mathrm{NADP}^{+}$reduction and 431 poising of cyclic electron flow (Okegawa et al. 2008), and $\Delta$ Flux was almost as large as $\mathrm{LEF}_{\mathrm{O} 2}$.

432 Using another method, Jia et al. (2008) observed that even at low irradiance ( 200 $433 \mu \mathrm{mol} \mathrm{m} \mathrm{m}^{-2} \mathrm{~s}^{-1}$ ) of red/far-red actinic light (centred at $697 \mathrm{~nm}$ ), CEF was as high as $40 \%$ of the 434 linear rate (corrected for an inhibitory effect of methyl viologen on PS II). Most probably, the 435 spectral distribution of the actinic light favoured cyclic electron flow over linear electron flow in 436 that study. The white incandescent actinic light used in this present study, more akin to sunlight, 
437 induced negligible $\Delta$ Flux below $350 \mu \mathrm{mol}$ photons $\mathrm{m}^{-2} \mathrm{~s}^{-1}$. This demonstrates the significant

438 effect of the spectral distribution of actinic light on the CEF being investigated. The present

439 method, which allows the use of white incandescent light, should give a reasonable estimate of

440 the magnitude of CEF in natural light.

$441 \quad$ Increasing temperature

442 Suggestions have been made that cyclic electron flow is activated by high temperature (Bukhov

443 et al. 1999; Clarke and Johnson, 2001). In our study, $\Delta$ Flux increased almost 3-fold when the

444 temperature was raised from $5^{\circ} \mathrm{C}$ to $40^{\circ} \mathrm{C}$ (Fig. 4). Even when $\mathrm{LEF}_{\mathrm{O} 2}$ declined between $32.5^{\circ} \mathrm{C}$

445 and $40^{\circ} \mathrm{C}, \Delta$ Flux did not decrease (Fig. 4). It has been reported that the temperature dependency

446 of LEF is not correlated with the temperature dependency of PS I activity but with that of

447 activity around PS II (Yamasaki et al. 2002; Yamori et al. 2008). Yamasaki et al. 2002

448 suggested, according to fluorescence decay analyses, that the temperature dependency of LEF

449 resides in electron transport between $\mathrm{Q}_{\mathrm{A}}$ and PS I. Although the carboxylation rate decreases at

450 high temperature, the oxygenation rate normally increases. The ATP/NADPH consumption

451 ratio is higher in oxygenation than in carboxylation. Therefore, CEF may be stimulated at high

452 temperature so as to meet the higher demand for ATP or compensating for the decrease in ATP

453 production caused by the decrease in activity around PS II, particularly if high temperature

454 facilitates the diffusion of ferredoxin or accelerated enzymatic reactions involved in CEF. It is

455 also possible that the increase in leakage of protons from the thylakoid lumen to the stroma at a

456 higher temperature caused the reversible activation of cyclic electron transport, as suggested by

457 Bukhov et al. (1999).

458 Loss of leaf water content

$459 \Delta$ Flux increased with water stress, here defined as the loss of tissue water (Fig. 5). Golding et al.

460 (2004) reported that water stress increased CEF when measured in the presence of DCMU and 
461 extremely high light. Similarly, Kohzuma et al. (2009) reported an increase in proton current at

462 a given $\mathrm{LEF}_{\mathrm{Fl}}$ measured in red light $\left(626 \mathrm{~nm}, \leq 300 \mu \mathrm{mol} \mathrm{m} \mathrm{m}^{-2} \mathrm{~s}^{-1}\right)$, in response to long-term 463 drought. By contrast, little change in CEF was observed by Jia et al. (2008) even when leaf 464 tissue had lost about $60 \%$ of its water; however, Jia et al. (2008) relied on a correction for the 465 partial inhibition of PS II by methyl viologen. A problem could have arisen because the 466 correction was based on Chl fluorescence. That CEF (as approximated by $\triangle$ Flux) increased, 467 certainly did not decrease, during severe water stress, despite the extreme macromolecular 468 crowdedness in the shrunken chloroplast stroma, is notable; it may be attributable to the 469 involvement of relatively small enzyme complexes in cyclic electron flow (Jia et al. 2008).

In conclusion, a simple non-intrusive method is here presented that estimates whole471 tissue $\Delta$ Flux under white light, $\Delta$ Flux being an upper estimate of CEF. Application of the 472 method in several treatments of spinach leaf discs yielded variations of the $\Delta$ Flux and, by 473 implication, CEF in ways that are expected. The estimates of CEF also showed a significant 474 difference between the present method using gross oxygen evolution to estimate the linear 475 electron flux and the previously-used method using Chl fluorescence to estimate the linear 476 electron flux; the previous method significantly over-estimates CEF even more.

\section{Acknowledgements}

478 This work was supported by a China Scholarship Council Fellowship (to JK), a JSPS 479 Postdoctoral Fellowship for Research Abroad (21-674) to R.O., a Knowledge Innovation 480 Programme of the Chinese Academy of Sciences grant (KSCX2-EW-J-1) to D.-Y. F., and 481 grants from the Australian Research Council to WSC (DP1093827) and to the CoE in Plant 482 Energy Biology (CE056195 to MRB). We thank Dr W. Yamori for his helpful comments.

\section{References}


484 Allen JF (2003) Cyclic, pseudocyclic and noncyclic photophosphorylation: new links in the 485 chain. Trends in Plant Science 8, 15-19

486

Alric J (2010) Cyclic electron flow around photosystem I in unicellular green algae. Photosynthesis Research 106, 47-56

Arnon DI, Whatley FR, Allen MB (1955) Vitamin K as a cofactor of photosynthetic phosphorylation. Biochimica et Biophysica Acta 16, 607-608

Atkin OK, Evans JR, Ball MC, Lambers H, Pons TL (2000) Leaf respiration of snow gum in the light and dark. Interactions between temperature and irradiance. Plant Physiology 122, 915923

Bailleul B, Cardol P, Breyton C, Finazzi G (2010) Electrochromism: a useful probe to study algal photosynthesis. Photosynthesis Research 106, 179-189

Bendall DS, Manasse R (1995) Cyclic photophosphorylation and electron transport. Biochimica et Biophysica Acta 1229, 23-38

Bukhov N, Carpentier R (2004) Alternative Photosystem I-driven electron transport routes: mechanisms and functions. Photosynthesis Research 82, 17-33

Bukhov NG, Wiese C, Neimanis S, Heber U (1999) Heat sensitivity of chloroplasts and leaves: Leakage of protons from thylakoids and reversible activation of cyclic electron transport. Photosynthesis Research 59, 81-93

Canaani O, Schuster G, Ohad I (1989) Photoinhibition in Chlamydomonas reinhardtii: Effect of state transition, intersystem energy distribution and Photosystem I cyclic electron flow. Photosynthesis Research 20, 129-146

Cardol P, Alric J, Girard-Bascou J, Franck F, Wollman FA, Finazzi G (2009) Impaired respiration discloses the physiological significance of state transitions in Chlamydomonas. Proceedings of the National Academy of Sciences USA. 106, 15979-15984 
508 Clarke JE, Johnson GN (2001) In vivo temperature dependence of cyclic and pseudocyclic 509 electron transport in barley. Planta 212, 808-816

510 Cleland RE, Bendall DS (1992) Photosystem I cyclic electron transport: Mesurement of 511 ferredoxin-plastoquinone reductase activity. Photosynthesis Research 34, 409-418

512 Driever SM, Baker NR (2011) The water-water cycle in leaves is not a major alternative 513 electron sink for dissipation of excess excitation energy when $\mathrm{CO}_{2}$ assimilation is restricted, $514 \quad$ Plant, Cell and Environment 34, 837-846

515 Endo T, Mi H, Shikanai T, Asada K (1997) Donation of electrons to plastoquinone by $516 \mathrm{NAD}(\mathrm{P}) \mathrm{H}$ dehydrogenase and by ferredoxin-quinone reductase in spinach chloroplasts. $517 \quad$ Plant and Cell Physiology 38, 1272-1277

518 Fan D-Y, Hope AB, Smith PJ, Jia H, Pace RJ, Anderson JM, Chow WS (2007a) The 519 stoichiometry of the two photosystems in higher plants revisited. Biochimica et Biophysica $520 \quad$ Acta $\mathbf{1 7 6 7 , 1 0 6 4 - 1 0 7 2}$

521 Fan D-Y, Nie Q, Hope AB, Hillier W, Pogson BJ, Chow WS (2007b) Quantification of cyclic 522 electron flow around Photosystem I in spinach leaves during photosynthetic induction. $523 \quad$ Photosynthesis Research 94, 347-357

524 Fan D-Y, Jia H, Barber J, Chow WS (2009) Novel effects of methyl viologen on photosystem II 525 function in spinach leaves. European Biophysics Journal 39, 191-199

526 Genty B, Briantais J-M, Baker NR (1989) The relationship between the quantum yield of 527 photosynthetic electron transport and quenching of chlorophyll fluorescence. Biochimica et 528 Biophysica Acta 990, 87-92

529 Golding AJ, Finazzi G, Johnson GN (2004) Reduction of the thylakoid electron transport chain 530 by stromal reductants - evidence for activation of cyclic electron transport upon dark 531 adaptation or under drought. Planta 220, 356-363 
532 Gotoh E, Matsumoto M, Ogawa K, Kobayashi Y, Tsuyama M (2010) A qualitative analysis of 533 the regulation of cyclic electron flow around photosystem I from the post-illumination 534 chlorophyll fluorescence transient in Arabidopsis: a new platform for the in vivo investigation of the chloroplast redox state. Photosynthesis Research 103, 111-123

Herbert SK, Fork DC, Malkin S (1990) Photoacoustic measurements in vivo of energy storage by cyclic electron flow in algae and higher plants. Plant Physiology 94, 926-934

Huang W, Zhang SB, Cao KF (2011) Cyclic electron flow plays an important role in

Ivanov B, Kobayashi Y, Bukhov NG, Heber U (1998) Photosystem I-dependent cyclic electron

545 flow in intact spinach chloroplasts: Occurrence, dependence on redox conditions and 546 electron acceptors and inhibition by antimycin A. Photosynthesis Research 57, 61-70

547 Jeanjean R, Latifi A, Matthijs HCP, Havaux M (2008) The PsaE subunit of photosystem I 548 prevents light-induced formation of reduced oxygen species in the cyanobacterium 549 Synechocystis sp. PCC 6803. Biochimica et Biophysica Acta 1777, 308-316

550 Jia H, Oguchi R, Hope AB, Barber J, Chow WS (2008) Differential effects of severe water 551 stress on linear and cyclic electron fluxes through Photosystem I in spinach leaf discs in $552 \quad \mathrm{CO}_{2}$-enriched air. Planta 228, 803-812

553 Joët T, Cournac L, Peltier G, Havaux M (2002) Cyclic electron flow around photosystem I in $\mathrm{C}_{3}$ 554 plants. In vivo control by the redox state of chloroplasts and involvement of the NADH555 dehydrogenase complex. Plant Physiology 128, 760-769 
556 Johnson GN (2005) Cyclic electron transport in $\mathrm{C}_{3}$ plants: fact or artefact? Journal of $557 \quad$ Experimental Botany 56, 407-416

558 Joliot P, Joliot A (2002) Cyclic electron transfer in plant leaf. Proceedings of the National $559 \quad$ Academy of Sciences USA 99, 10209-10214

560 Joliot P, Joliot A (2005) Quantification of cyclic and linear flows in plants. Proceedings of the $561 \quad$ National Academy of Sciences USA 102: 4913-4918

562 Joliot P, Joliot A (2006) Cyclic electron flow in C3 plants. Biochimica et Biophysica Acta 1757, $563 \quad 362-368$

564 Kim S-J, Lee C-H, Hope AB, Chow WS (2001) Inhibition of photosystems I and II and 565 enhanced back flow of photosystem I electrons in cucumber leaf discs chilled in the light. $566 \quad$ Plant and Cell Physiology 42, 842-848

567 Klughammer C, Schreiber U (1994) An improved method, using saturating light pulses, for the 568 determination of photosystem I quantum yield via $\mathrm{P} 700^{+}$-absorbance changes at $830 \mathrm{~nm}$. $569 \quad$ Planta 192, 26-268

570 Klughammer C, Schreiber U (2007) Saturation Pulse method for assessment of energy 571 conversion in PS I. http://www.walz.com/e journal/pdfs/PAN07002.pdf

572 Kohzuma K, Cruz JA, Akashi K, Hoshiyasu S, Munekage YN, Yokota A, Kramer DM (2009) 573 The long-term responses of the photosynthetic proton circuit to drought. Plant Cell and 574 Environment 32, 209-219

575 Kramer DM, Evans JR (2011) The importance of energy balance in improving photosynthetic 576 productivity. Plant Physiology 155, 70-78

577 Krause GH, Weis E (1991) Chlorophyll fluorescence and photosynthesis: the basics. Annual $578 \quad$ Review of Plant Biology 42, 301-313 
579 Laisk A, Eichelmann H, Oja V, Peterson RB (2005) Control of cytochrome $b_{6} f$ at low and high 580 light intensity and cyclic electron transport in leaves. Biochimica et Biophysica Acta 1708, $581 \quad 79-90$

582 Laisk A, Talts E, Oja V, Eichelmann H, Peterson RB (2010) Fast cyclic electron transport 583 around photosystem I in leaves under far-red light: a proton-uncoupled pathway? $584 \quad$ Photosynthesis Research 103, 79-95

585 Livingston AK, Kanazawa A, Cruz JA, Kramer DM (2010) Regulation of cyclic electron flow 586 in $\mathrm{C}_{3}$ plants: differential effects of limiting photosynthesis at ribulose-1,5-bisphosphate 587

Losciale P, Oguchi R, Hendrickson L, Hope AB, Corelli-Grappadelli L, Chow WS (2008) A 590 rapid, whole-tissue determination of the functional fraction of Photosystem II after 591 photoinhibition of leaves based on flash-induced P700 redox kinetics. Physiologia 592 Plantarum 132, 23-32

593 Malkin S, Canaani O (1994) The use and characteristics of the photoacoustic method in the 594 study of photosynthesis. Annual Review of Plant Physiology and Plant Molecular Biology 45, $595 \quad 493-526$

596 Mano J, Miyake C, Schreiber U, Asada K (1995) Photoinactivation of the electron flow from 597 NADPH to plastoquinone in spinach chloroplasts. Plant and Cell Physiology 36, 1589-1598

598 Maxwell PC, Biggins J (1976) Role of cyclic electron transport in photosynthesis as measured 599 by the photoinduced turnover of $\mathrm{P}_{700}$ in vivo. Biochemistry 15, 3975-3981

600 McCree KJ (1972) The action spectrum, absorptance and quantum yield of photosynthesis in 601 crop plants. Agricultural Meteorology 9, 191-216 
602 Miyake C (2010) Alternative electron flows (water-water cycle and cyclic electron flow around 603 PS I) in photosynthesis: molecular mechanisms and physiological functions. Plant and Cell $604 \quad$ Physiology 51, 1951-1963

605

606

607

609

610

Miyake C, Miyata M, Shinzaki Y, Tomizawa $\mathrm{K}$ (2005) $\mathrm{CO}_{2}$ response of cyclic electron flow around PS I (CEF-PS I) in tobacco leaves - Relative electron fluxes through PS I and PS II determine the magnitude of non-photochemical quenching (NPQ) of Chl fluorescence. Plant and Cell Physiology 46, 629-637

Moss DA, Bendall DS (1984) Cyclic electron transport in chloroplasts. The Q-cycle and the site of action of antimycin. Biochimica et Biophysica Acta 767, 389-395

Munekage Y, Hashimoto M, Miyake C, Tomizawa KI, Endo T, Tasaka M, Shikanai T (2004) Cyclic electron flow around photosystem I is essential for photosynthesis. Nature 429, 579582

Oguchi R, Douwstra P, Fujita T, Chow WS, Terashima I (2011) Intra-leaf gradients of photoinhibition induced by different color lights: Implications for the dual mechanisms of photoinhibition and for the application of conventional chlorophyll fluorometers. New Phytologist 191, 146-159

Okegawa Y, Kagawa Y, Kobayashi Y, Shikanai T (2008) Characterization of factors affecting the activity of photosystem I cyclic electron transport in chloroplasts. Plant and Cell Physiology 49, 825-834

Oxborough K, Baker NR (1997) Resolving chlorophyll $a$ fluorescence images of photosynthetic efficiency into photochemical and non-photochemical components-calculation of $q P$ and $F_{\mathrm{v}}{ }^{\prime} / F_{\mathrm{m}}{ }^{\prime}$ without measuring $F_{\mathrm{o}}{ }^{\prime}$. Photosynthesis Research 54, 135-142

Ruuska SA, Badger MR, Andrews TJ, von Caemmerer S (2000) Photosynthetic electron sinks in transgenic tobacco with reduced amounts of Rubisco: little evidence for significant Mehler reaction. Journal of Experimental Botany 51, 357-368 
627 Sacksteder CA, Kramer DM (2000) Dark interval relaxation kinetics of absorbance changes as a 628 quantitative probe of steady-state electron transfer. Photosynthesis Research 66, 145-158

629 Schreiber U (2004) Pulse-amplitude-modulation (PAM) fluorometry and saturation pulse 630 method: an overview. In: Chlorophyll a fluorescence: a signature of photosynthesis. Edited 631 by Papageorgiou, G.C., Govindjee, pp 279-319. Springer, Dordrecht, The Netherlands 632 Shikanai T (2007) Cyclic electron transport around photosystem I: genetic approaches. Annual 633 Review of Plant Biology 58, 199-217

634 Siebke K, von Caemmerer S, Badger MR, Furbank RT (1997) Expressing an RbcS antisense 635

Takahashi S, Milwood SE, Fan DY, Chow WS, Badger MR (2009) How does cyclic electron flow alleviate photoinhibition in ArabidoPS Is? Plant Physiology 149, 1560-1567

Terashima I, Fujita T, Inoue T, Chow WS, Oguchi R (2009) Green light drives leaf 640 photosynthesis more efficiently than red light in strong white light: Revisiting the enigmatic 641 question of why leaves are green. Plant and Cell Physiology 50, 684-697

642 Tsuyama M, Shibata M, Kobayashi Y (2003) Leaf factors affecting the relationship between 643 chlorophyll fluorescence and the rate of photosynthetic electron transport as determined from $644 \quad \mathrm{CO}_{2}$ uptake. Journal of Plant Physiology 160, 1131-1139

645 Veeranjaneyulu K, Charland M, Leblanc RM (1998) High-irradiance stress and photochemical 646 activities of photosystems 1 and 2 in vivo. Photosynthetica 35, 177-190

647 Vredenberg WJ, Bulychev AA (2010) Photochemical control of the balance between cyclic- and 648 linear electron transport in photosystem I. Algorithm for $\mathrm{P} 700^{+}$induction kinetics. $649 \quad$ Biochimica et Biophysica Acta 1797, 1521-1532 
650 Yamasaki T, Yamakawa T, Yamane Y, Koike H, Satoh K, Katoh S (2002) Temperature 651 acclimation of photosynthesis and related changes in photosystem II electron transport in $652 \quad$ winter wheat. Plant Physiology 128, 1087-1097

653 Yamori W, Noguchi K, Kashino Y, Terashima I (2008) The role of electron transport in 654 determining the temperature dependence of the photosynthetic rate in spinach leaves grown 655 at contrasting temperatures. Plant and Cell Physiology 49, 583-591

656 
657 Table 1. Various ways of monitoring the cyclic electron flux (CEF).

\begin{tabular}{llll}
\hline Using & $\begin{array}{l}\text { Un- } \\
\text { Inhibitor(s) } \\
\text { natural } \\
\text { light }\end{array}$ & & \multicolumn{1}{c}{$\begin{array}{c}\text { Subtracting LEF from } \\
\text { combined (LEF + CEF) measurement: }\end{array}$} \\
\cline { 3 - 4 } & & $\begin{array}{l}\mathrm{LEF}_{\mathrm{Fl}} \text { by Chl } \\
\text { fluorescence as an } \\
\text { estimate of LEF }\end{array}$ & $\begin{array}{l}\mathrm{LEF}_{\mathrm{O} 2} \text { by }_{2} \\
\text { evolution or } \mathrm{CO}_{2} \\
\text { fixation }\end{array}$ \\
\end{tabular}

\section{(A) CEF measurement}

(1) Post-illumination Chl a fluorescence transient (qualitative)

(2) post-illumination b ferredoxin redox kinetics

(3) Photoacoustics

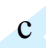

d

(B) Combined (LEF + CEF) measurement

(i) Electrochromic signal e (DIRK)

(ii) $\mathrm{P} 700^{+}$reduction

g kinetics

$\mathrm{c}$

(iii) $\mathrm{P} 700^{+}$for PS I photochemical yield

f

$\mathrm{h}, \mathrm{j}$

\section{i}

$\mathrm{k}$ f

(1)

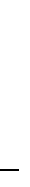

\section{.}

(1) 
668 Table 2. An estimation of the fraction of absorbed light $\left(f_{\mathrm{I}}\right)$ partitioned to PS I

669

\begin{tabular}{|c|c|c|c|c|}
\hline $\begin{array}{c}\text { Antimycin A } \\
(\mu \mathrm{M})\end{array}$ & $\begin{array}{c}\text { Irradiance } \\
\left(\mu \mathrm{mol} \text { photons } \mathrm{m}^{-2} \mathrm{~s}^{-1}\right)\end{array}$ & $\mathbf{Y}(\mathrm{I})$ & 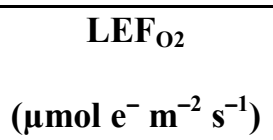 & $f_{\mathrm{I}}$ \\
\hline 150 & 980 & $0.403 \pm 0.019$ & $165 \pm 6$ & 0.49 \\
\hline 200 & 980 & $0.397 \pm 0.016$ & $156 \pm 5$ & 0.47 \\
\hline 0 & 236 & $0.747 \pm 0.014$ & $67 \pm 5$ & 0.45 \\
\hline 0 & 352 & $0.738 \pm 0.013$ & $107 \pm 5$ & 0.48 \\
\hline
\end{tabular}

670

$671 \mathrm{Y}(\mathrm{I})$ is the photochemical yield of PS $\mathrm{I}$, and $\mathrm{LEF}_{\mathrm{O} 2}$ the linear electron flux determined by the

672 gross rate of $\mathrm{O}_{2}$ evolution. Values are mean \pm s.e. $(\mathrm{n}=14-15$ leaf discs).

673 

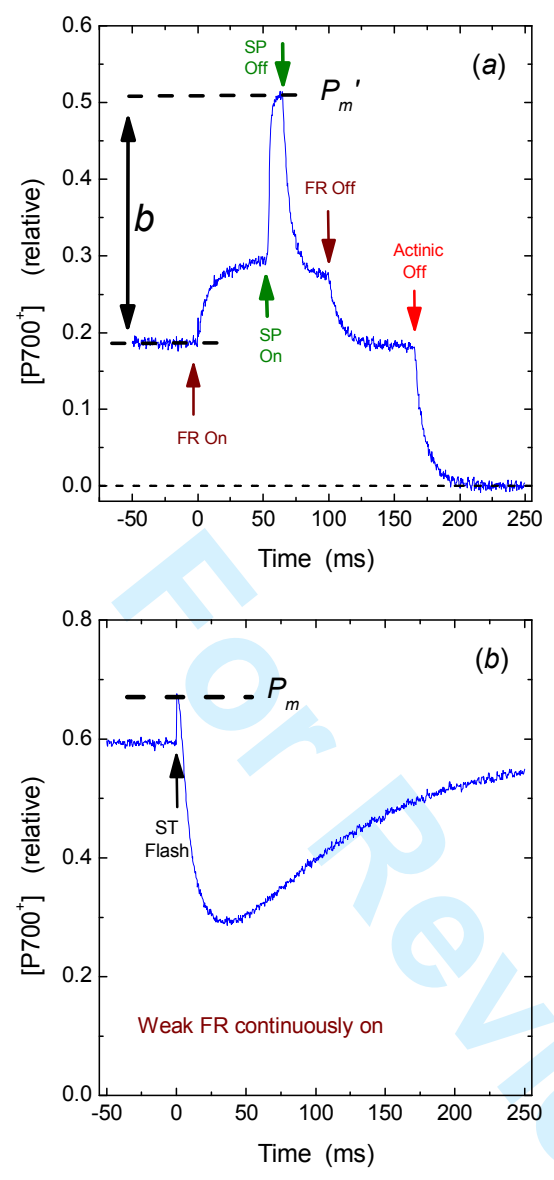

674

675 Fig. 1. An example of the measurement of the photochemical yield of PS I in two parts. (a)

676 Steady-state photosynthesis in white light $\left(980 \mu \mathrm{mol} \mathrm{m} \mathrm{m}^{-2} \mathrm{~s}^{-1}\right)$ was occurring with a steady

677 concentration of $\mathrm{P} 70^{+}$, when strong far-red light (FR, $2000 \mu \mathrm{mol} \mathrm{m} \mathrm{m}^{-2}$ ) was turned on at time

$678 t=0$ for $100 \mathrm{~ms}$ to further photo-oxidize P700. At $t=50 \mathrm{~ms}$, a $10-\mathrm{ms}$ saturating light pulse (SP,

$6799000 \mu \mathrm{mol} \mathrm{m} \mathrm{s}^{-2}$ ) was applied to fully photo-oxidize P700. FR was turned off at $t=100 \mathrm{~ms}$,

680 followed by cessation of actinic illumination at $t=166 \mathrm{~ms}$. The signal relaxed to a baseline

681 corresponding to fully reduced P700. The signal interval $b$ represents the P700 still available to

682 be photo-oxidized during illumination at a particular irradiance. The signal is an average of 9

683 traces $(<1 \mathrm{~s}$ between two consecutive repeats). (b) The maximum amount of photo-oxidizable

684 P700 was obtained by first illuminating a leaf disc with weak continuous far-red light to attain

685 about $88 \%$ oxidation in the steady state. Then a single-turnover (ST) saturating xenon flash was

686 applied to photo-oxidize the remainder of the P700. The peak immediately after the flash was

687 taken to be $P_{\mathrm{m}}$. The signal is an average of 9 traces. The ratio $b / P_{\mathrm{m}}$ is the photochemical yield

688 of PS I (Klughammer and Schreiber 2007). 

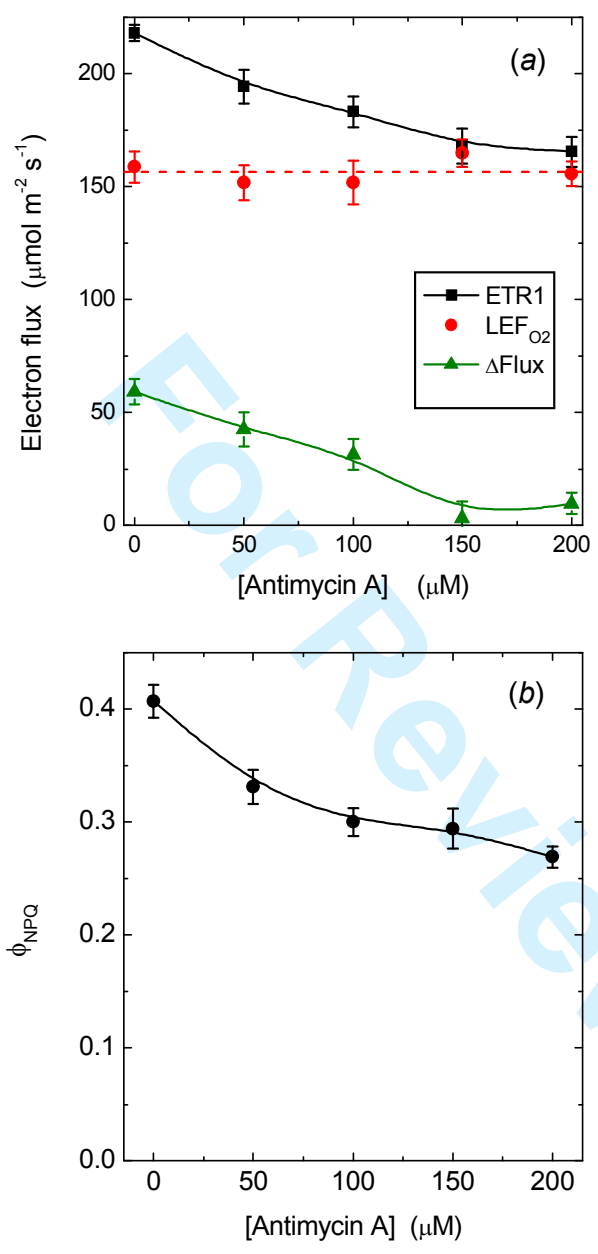

692

693

694 Fig. 2. (a) Variation of steady-state electron fluxes with [antimycin A] used to infiltrate leaf tissue. A fixed irradiance of $980 \mu \mathrm{mol} \mathrm{m} \mathrm{m}^{-2}$ was used. Values are means \pm s.e. $(\mathrm{n}=15$ leaf discs). (b) $\phi_{\mathrm{NPQ}}$, the fraction of light absorbed by the PS II antennae that is dissipated thermally via $\Delta \mathrm{pH}-$ and xanthophylls-regulated processes is plotted against [antimycin $\mathrm{A}$ ]. 


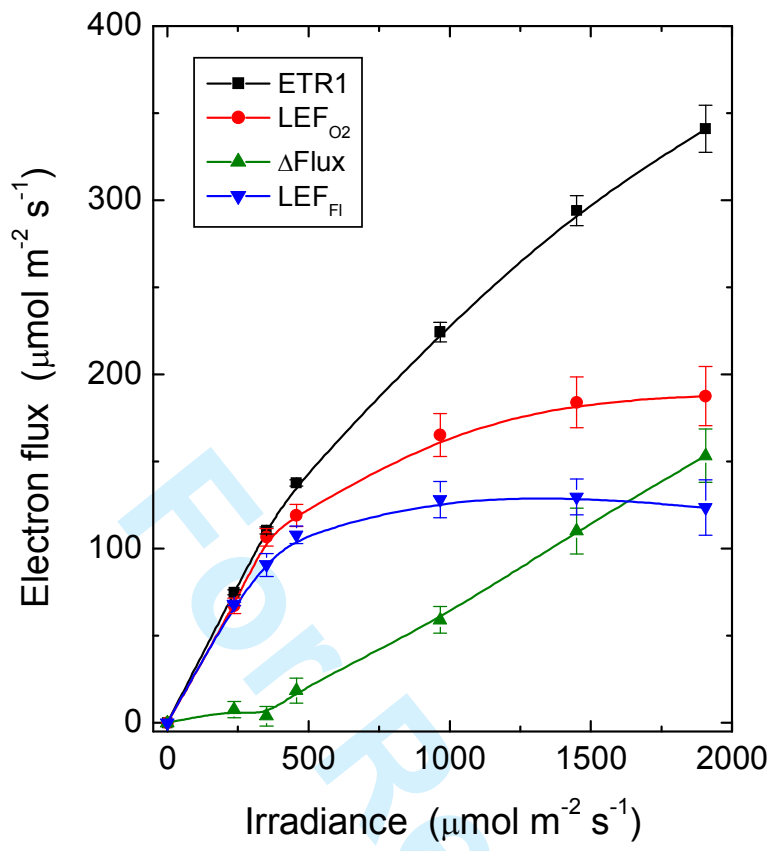

700

701

702 Fig. 3. Response of steady-state electron fluxes to irradiance of white light. ETR1 represents 703 the total electron flux through PS I, and $\mathrm{LEF}_{\mathrm{O} 2}$ (the gross oxygen evolution rate multiplied by 704 four) represents the linear electron flux through both photosystems, both being whole-tissue 705 steady-state measurements. $\mathrm{CEF}_{\mathrm{O} 2}=\mathrm{ETR} 1-\mathrm{LEF}_{\mathrm{O} 2} . \mathrm{LEF}_{\mathrm{F} 1}$ is a measure of the electron flux 706 through PS II based on Chl fluorescence emitted from a certain depth in the leaf tissue. Each 707 leaf disc was exposed to an irradiance that increased from 0 to the maximum using white 708 halogen light filtered through neutral density filters. The leaf disc was maintained at each 709 irradiance for about $10 \mathrm{~min}$ to reach steady-state photosynthesis. Oxygen evolution and Chl 710 fluorescence were first measured simultaneously. Immediately afterwards P700 kinetics were 711 measured while maintaining steady state. The temperature was $25^{\circ} \mathrm{C}$. Values are means \pm s.e. $712 \quad(\mathrm{n}=14$ leaf discs $)$. 


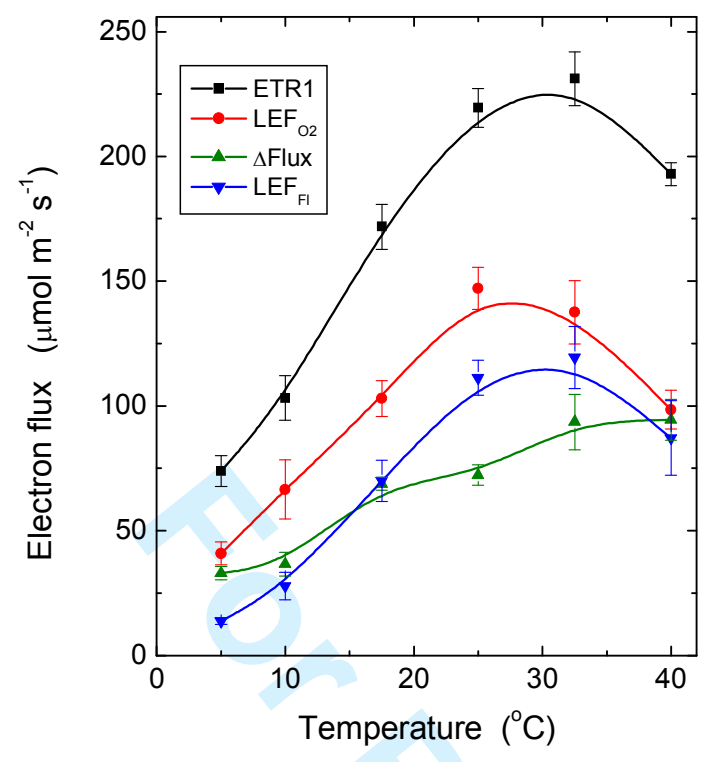

715

716

717 Fig. 4. Variation of steady-state electron fluxes with leaf temperature, at $980 \mu$ mol photos $\mathrm{m}^{-2}$

$718 \mathrm{~s}^{-1}$. The leaf temperature was controlled by thermostatting the temperature of the gas-phase $\mathrm{O}_{2}$

719 electrode chamber at the desired temperature. Other conditions are described in Fig. 3. Values

720 are means \pm s.e. $(n=14$ leaf discs $)$.

721 


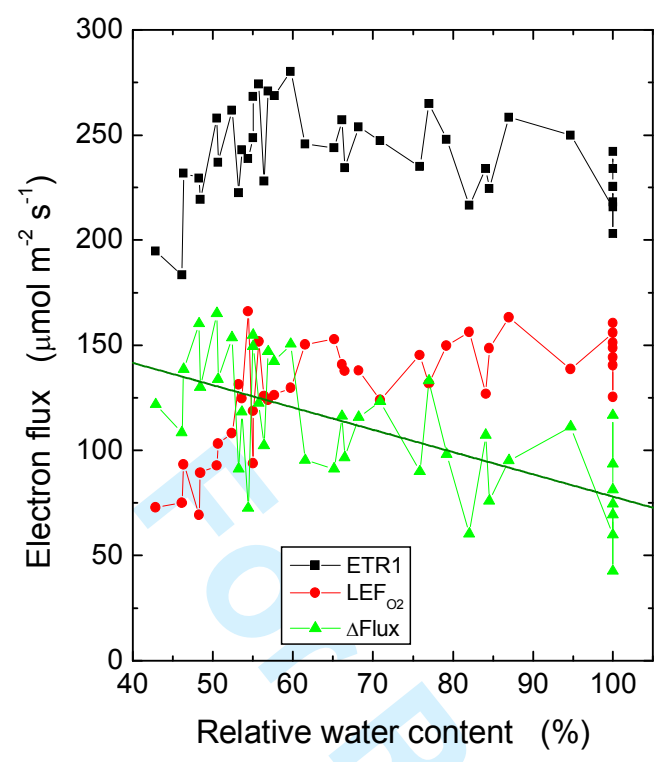

723

724

725 Fig. 5. (a) Variation of steady-state electron fluxes with the relative water content of leaf tissue,

726 at $980 \mu \mathrm{mol}$ photons $\mathrm{m}^{-2} \mathrm{~s}^{-1}$. The straight line is a linear regression line through the points.

727 Other conditions are described in Fig. 3. 